\title{
Aislamiento de una bacteria endófita de vainilla (Vanilla planifolia) con actividad biocontroladora in vitro contra Fusarium oxysporum f. sp. Vanillae
}

Isolation of vanilla-endophytic bacteria (Vanilla planifolia) with in vitro biocontrol activity against Fusarium oxysporum f. sp. Vanillae

\section{Karol Jiménez-Quesada1', Alexander Schmidt-Durán², Kevin Quesada- Montero $^{3}$, Ileana Moreira-González ${ }^{4}$}

Jiménez-Quesada, K; Schmidt-Durán, A; Quesada-Montero, K, Moreira-González, I. Aislamiento de una bacteria endófita de vainilla (Vanilla planifolia) con actividad biocontroladora in vitro contra Fusarium oxysporum f. sp. Vanillae. Tecnología en Marcha. Vol. 28, № 2, Abril-Junio. Pág 116-125.

1 Centro de investigación en Biotecnología (CIB), Instituto Tecnológico de Cota Rica. Correo electrónico: kjimenez@itcr.ac.cr

2 Centro de investigación en Biotecnología (CIB), Instituto Tecnológico de Cota Rica. Correo electrónico: aschmidt@itcr.ac.cr

3 Carrera de Ingeniería en Biotecnología, Instituto Tecnológico de Cota Rica. Correo electrónico: kevin707qm@hotmail.com

4 Centro de investigación en Biotecnología (CIB), Instituto Tecnológico de Cota Rica. Correo electrónico: imoreira@itcr.ac.cr 
Tecnología en Marcha,

Vol. 28, N. 2, Abril-Junio 2015117

\title{
Palabras clave
}

Antagonismo; cultivo orgánico; fermentación; inductor biótico; sistema agroforestal.

\section{Resumen}

El género Vanilla pertenece a la familia Orchidaceae. Algunas de sus especies con interés comercial son $V$. planifolia, $V$. pompona y $V$. tahitensis. La clasificación de la calidad de la vainilla se efectúa según el largo de la cápsula y el contenido de vainillina, la cual se utiliza para elaborar alimentos y bebidas, como materia prima en la industria farmacéutica y en la producción de cosméticos y perfumes, entre otros usos. Se considera que el mayor problema que enfrenta la producción de vainilla es la pudrición de la raíz ocasionada por el hongo Fusarium oxyporum f. sp. Vanillae, que provoca entre $30-52 \%$ de la muerte de las plantas al atacar las raíces adventicias, impidiéndoles absorber agua y nutrientes. El hongo no puede erradicarse por la acción de agroquímicos ya que dañan la viabilidad de las plantas; además, el cultivo de vainilla sin la aplicación de agroquímicos de manera orgánica en sistemas agroforestales es una actividad que está cobrando gran interés entre los pequeños productores del país. Es por tal razón que en esta investigación se evaluó la capacidad de control de bacterias endófitas aisladas de muestras de vainilla procedentes de Corcovado, Puriscal, Dota y Guápiles, mediante pruebas de antagonismo in vitro entre la bacterias aisladasy el hongo $F$. oxysporum. El resultado es que la cepa bacteriana B1M11 es una candidata promisoria para responder al ataque del patógeno, lo que se corroboró con la aparición de un halo de inhibición del crecimiento del hongo en placa.

\section{Keywords}

Agroforestry system; antagonism; biotic inductor; fermentation; organic culture system.

\begin{abstract}
Vanilla sp. genus belongs to Orchidaceae family, and V. planifolia, V. pompona and $V$. tahitensis. are species of commercial interest. The quality classification of vanilla is made according to the length of the capsule and vanillin content, which is used to make food and beverage, as raw material in the pharmaceutical industry and for the production of cosmetics and perfumes, among others. Currently, root rot caused by the fungus Fusarium oxyporum f. sp. Vanillae is considered to be the biggest problem facing vanilla production, causing 30 to $52 \%$ of plant death, attacking adventitious roots and preventing this plant is able to absorb water and nutrients. The fungus cannot be eradicated by the action of chemicals that damage the viability of the plants, and because the cultivation of vanilla in agroforestry systems without the application of agrochemicals is an activity that is gaining interest among small producers country. It is for this reason why was studied the ability of control of vanilla endophytic bacteria isolated from samples from Corcovado, Puriscal, Dota and Guápiles, by testing in vitro antagonism between asylee bacteria and fungus F. oxysporum, giving results about promising candidate B1M11 to respond to pathogen attack, which was corroborated by the appearance of a halo of inhibition of fungal growth on plate.
\end{abstract}

\section{Introducción}

El género Vanilla pertenece a la familia Orchidaceae, siendo $V$. planifolia, $V$. pompona y $V$. thaitensis las únicas especies de orquídeas que producen frutos comestibles (Paniagua, 2013). 
La sustancia responsable de la fragancia peculiar y el sabor de la vainilla es la vainillina $\left(\mathrm{C}_{8} \mathrm{H}_{8} \mathrm{O}_{3}\right)$ que se encuentra en una concentración de 0,75 a 3,7\% en la vaina y se relaciona directamente con la calidad del fruto (González et al., 2009). En Costa Rica, se tienen registros del cultivo de vainilla en Pérez Zeledón, Bocana de Puriscal, San Isidro de Dota, Quepos, La Cruz, Guápiles, Cutris, Florencia y Upala, que se realiza a partir de semilla proveniente del cultivo de tejidos y por esqueje o bejuco de al menos ocho nudos para asegurar un buen enraizamiento (Varela, 2011).

Se estima que el mayor problema que enfrenta la producción de vainilla es la pudrición de la raíz ocasionada por el hongo F. oxyporum f. sp. Vanillae, que causa entre 30-52\% de la muerte de las plantas, atacando las raíces adventicias e impidiendo así que la planta sea capaz de absorber agua y nutrientes. La aparición de F. oxysporum es favorecida por el exceso de sombra y las altas precipitaciones, así como los suelos degradados y la escasez de materia orgánica (Olivares, 2010).

Fusarium sp. es un hongo patógeno que se caracteriza por crecer formando colonias de diversos colores -blanco, rosado pálido, rojo, anaranjado, púrpura, celeste, verde aceituna- de manera moderada a rápida. El micelio de este hongo puede ser ralo o denso, algodonoso con funículos o limoso. Además, los pigmentos que difunden en el agar suelen variar de color o tono con el pH (Carrillo, 2003).

La relación de este hongo con la afectación en los cultivos de vainilla está dada por el efecto de la cepa Fusarium oxysporum f. sp. vanillae. La sintomatología se inicia con la aparición de lesiones de color café oscuro en los tallos de vainilla, junto con zonas cloróticas en los entrenudos, hasta que se produce la necrosis, reducción y muerte del tejido, que se traslada progresivamente del tallo al nudo (He, 2007). Por su parte, cuando el ataque del hongo se inicia en la raíz, el daño desciende a partir de las raíces adventicias. En condiciones de alta humedad, la pudrición es suave; la proliferación de micelio y conidios se presenta sobre el tejido dañado, agudizando el inóculo en la plantación (Bhai y Dhanesh, 2008).

La problemática principal alrededor del combate de F. oxysporum es que los fungicidas para el control de este hongo perturban el ciclo de interacción entre los hongos micorrizógenos nativos que integran la rizosfera de la vainilla, provocando una ocasional o casi nula reproducción por semilla en la naturaleza, y probablemente una disminución en la capacidad de absorción de nutrientes por las raíces adventicias (Gätjens y Montero, 2012).

Debido a esto, los vainilleros de Costa Rica han optado por el cultivo de vainilla orgánica en sistemas agroforestales, para garantizar un producto libre de agroquímicos que no perturben la calidad ni dañen la fisiología de las plantas. No obstante, esta decisión está vinculada directamente con el aumento de las precauciones para evitar la aparición del hongo (Kistler, 1997; Villalba, Moreira y Díaz, 2012).

El cultivo de vainilla sin aplicación de agroquímicos es quizás una de las actividades más importantes entre los agricultores directamente involucrados en su producción en Costa Rica. Esto hace que sea necesario dotarlos de herramientas tecnológicas que les permitan seguir manejando sus sistemas de producción según un modelo orgánico (Villalba et al., 2012).

El control biológico en cultivos perennes como las orquídeas enfrenta grandes retos, principalmente por la ausencia de rotación de cultivos para reducir los niveles de inóculo de un determinado patógeno. Lo anterior incrementa el riesgo de plagas en una plantación. Una alternativa es evaluar bacterias endófitas de vainilla que demuestren en pruebas in vitro que poseen un potencial biocontrolador para hongos del suelo, con el propósito de conocer su impacto en el desarrollo y establecimiento del cultivo y la posible aparición de enfermedades 
del suelo como posibles inductores de resistencia en las plantas inoculadas en los sistemas de producción orgánica (Paniagua, Villalba y Montero, 2011).

Los microorganismos endófitos son aquellos que habitan en los tejidos internos de una planta sin resultar patógenos para ella. En general, la investigación ha demostrado que los endófitos bacterianos pueden ser un factor clave en la reducción de la herbivoría, la promoción del crecimiento de la planta, el aumento de la absorción de minerales, la fijación de nitrógeno, la supresión de enfermedades y la inducción de cascadas de defensa (Melnick, Bailey y Backman, 2012).

El objetivo de esta investigación fue evaluar el efecto biocontrolador in vitro de las bacteria endófitas aisladas en el cultivo de la vainilia (Vainilla sp.), para el combate biológico de la marchitez causada por el hongo F. oxysporum.

\section{Materiales y métodos}

La presente investigación se llevó a cabo en los laboratorios de Biocontroladores y Biología Molecular del Centro de Investigación en Biotecnología (CIB) del Instituto Tecnológico de Costa Rica (ITCR), sede Cartago.

\section{Recolección del material vegetal}

El material de vainilla necesario para el aislamiento de bacterias endófitas de interés se recolectó en diferentes regiones del país: Bocana de Puriscal y San Isidro de Dota (San José), Barra de Parismina y La Colonia de Guápiles (Limón), Upala (Alajuela) y en la Península de Osa (Puntarenas); también se obtuvo material de invernadero procedente de la aclimatación de plantas in vitro del Instituto de Investigación y Servicios Forestales (INISEFOR-UNA). El protocolo de recolección consistió en el corte de esquejes de 30-40 cm de plantas de vainilla adultas, que contuvieran aproximadamente 2 ó 3 nudos, utilizando una cuchilla y sellando los cortes con cloro comercial (3,5\% i.a.). Se procedió con el corte de los esquejes, seleccionando aquellos que fisiológicamente se observaran sanos y afectados por el hongo F. oxysporium.

\section{Aislamiento de bacterias endófitas}

Se desinfectó el tejido superficial de los tallos. Para esto se utilizaron fragmentos de aproximadamente $10 \mathrm{~cm}$, que se trasladaron a la cámara de flujo laminar y se colocaron en una solución de hipoclorito de sodio al 0,5\% (3,5\% i.a.) durante 10 minutos; transcurrido ese tiempo, se lavaron los explantes con agua destilada estéril, luego con alcohol al $70 \%$ durante 30 segundos y posteriormente con agua destilada una vez más. Concluida la desinfección, cada muestra se trasladó a un mortero para macerarlas manualmente utilizando $10 \mathrm{ml}$ de PBS 1\%; a partir de cada macerado se prepararon dos diluciones $\left(10^{-1}\right.$ y $\left.10^{-2}\right)$ y de cada de ellas una se tomó $1 \mathrm{ml}$ para inocular en medio Agar Papa Dextrosa (PDA) y Agar Nutritivo (AN), dando como resultado un total de cuatro placas inoculadas por muestra, mantenidas a $30 \pm 1{ }^{\circ} \mathrm{C}$ por un período de tres días para AN y de una semana a temperatura ambiente para PDA, antes de su evaluación.

\section{Purificación de los aislamientos}

Transcurrido el período de incubación de los macerados, se evaluaron las placas, separando las colonias que presentaban diferente morfología y/o coloración y obteniendo cultivos puros de las mismas. 


\section{Pruebas de antagonismo in vitro}

Las pruebas de antagonismo realizadas consistieron en inocular en placas con medio de cultivo AN un segmento de $5 \mathrm{~mm}^{2}$ del hongo $F$. oxysporum colocado en el centro de la placa y cuatro bacterias endófitas obtenidas de los aislamientos, equidistantemente inoculadas por traspaso con asa bacteriológica. La cepa del hongo fue facilitada por la empresa Plantech S. A. En total se realizaron ocho ensayos por duplicado, para un total de 30 bacterias morfológicamente diferentes analizadas. El periodo de incubación del ensayo fue de dos semanas a $30 \pm 1^{\circ} \mathrm{C}$.

\section{Selección de la cepa bacteriana con potencial biocontrolador}

Una vez ejecutadas las pruebas de antagonismo en placa entre la diferentes bacterias aisladas ante el hongo F. oxysporum, los criterios de selección de la cepa de interés se determinaron según presencia/ausencia de un halo de inhibición definido, observable a simple vista.

\section{Resultados y discusión}

\section{Recolección del material vegetal}

El material de Vanilla sp. recolectado para ser procesado y hacer la bioprospección de las bacterias endófitas provenía de diversos lugares del país, como se observa en el cuadro 1.

Cuadro 1. Descripción de muestras de Vainilla sp. recolectadas en diversas regiones de Costa Rica para utilizarlas en el aislamiento de bacterias endófitas

\begin{tabular}{|c|c|c|c|c|}
\hline No muestra & Especie & Región de procedencia & Otros datos & $\begin{array}{c}\text { Estado fisiológico } \\
\text { del material }\end{array}$ \\
\hline 1 & V. planifolia & $\begin{array}{c}\text { Material in vitro } \\
\text { INISEFOR }\end{array}$ & Ensayo de aclimatación & Sano \\
\hline 2 & No especificada & Barra de Parismina & Orilla de la playa & Sano \\
\hline 3 & No especificada & Península de Osa & $\begin{array}{c}\text { Playa Blanca, Puerto } \\
\text { Escondido }\end{array}$ & Sano \\
\hline 4 & $\begin{array}{c}\text { Híbrido, cruce entre V. } \\
\text { planifolia y V. pompona }\end{array}$ & Península de Osa & $\begin{array}{c}\text { Gallardo, Alfredo Mesén, } \\
\text { planta madre, }\end{array}$ & Sano \\
\hline 5 & No especificada & Península de Osa & $\begin{array}{c}\text { Corcovado Finca Andrés } \\
\text { Plani }\end{array}$ & Sano \\
\hline 6 & V. pompona & Upala & Bosque & Sano \\
\hline 7 & No especificada & Península de Osa & Finca Gilbar & Sano \\
\hline 8 & V. planifolia & San Isidro de Dota & Finca Onde Chinchilla & Enfermo \\
\hline 9 & V. planifolia & Bocana, Puriscal & Finca Eugenia Garro & Sano \\
\hline 10 & V. pompona & La Colonia de Guápiles & Finca Juan Carvajal & Sano \\
\hline 11 & V. pompona & La Colonia de Guápiles & Finca Juan Carvajal & Enfermo \\
\hline
\end{tabular}


La muestra 1 fue la única que se obtuvo a partir de una planta joven proveniente del cultivo in vitro de $V$. planifolia. Por otra parte, las muestras 2, 3 y 6 provenían de plantas adultas que crecieron naturalmente en un hábitat como bosque y playa. Finalmente, la muestras 4, 5, 7, 8, 9, 10 y 11 se recolectaron a partir de plantas adultas cuyo crecimiento se ha adecuado dentro de un sistema agroforestal. Los sistemas agroforestales son una forma de uso de la tierra en el que plantas leñosas perennes (árboles) interactúan biológicamente en un área con cultivos y/o animales, con el propósito fundamental de diversificar y optimizar la producción respetando el principio de la sostenibilidad. Generalmente, es el árbol el que contribuye con productos adicionales, mejora el suelo, el microclima o sirve de tutor (Varela, 2011).

Se determinó que las muestras 8 y 11 se encontraban evidentemente afectadas por el hongo F. oxysporum, puesto que mostraban la sintomatología característica del ataque del patógeno, como las lesiones café oscuro en los tallos y necrosis y reducción de los tejidos en algunas zonas, aunado a la pudrición de la raíz (Bhai y Dhanesh, 2008). La aparición del hongo en una plantación o en un sistema agroforestal puede deberse a que el terreno retiene altos porcentajes de humedad y tiene grandes extensiones de sombra, siendo el exceso de estos dos factores una causa común de la aparición del patógeno (Olivares, 2010).

En cuanto a las muestras sanas, se observaron en buen estado fisiológico, con un color verde intenso y raíces arraigadas al soporte natural sobre el que han crecido. Algunas de las muestras sanas recolectadas se encontraron asociadas a tutores de Erythrina berteroana (poró) y Acnistus arborescens (güitite), como se observa en la figura 1, y dentro de un sistema agroforestal con árboles de cítricos y Gliricidia sepium (madero negro), principalmente, creando con esto los tres niveles de altura recomendados.

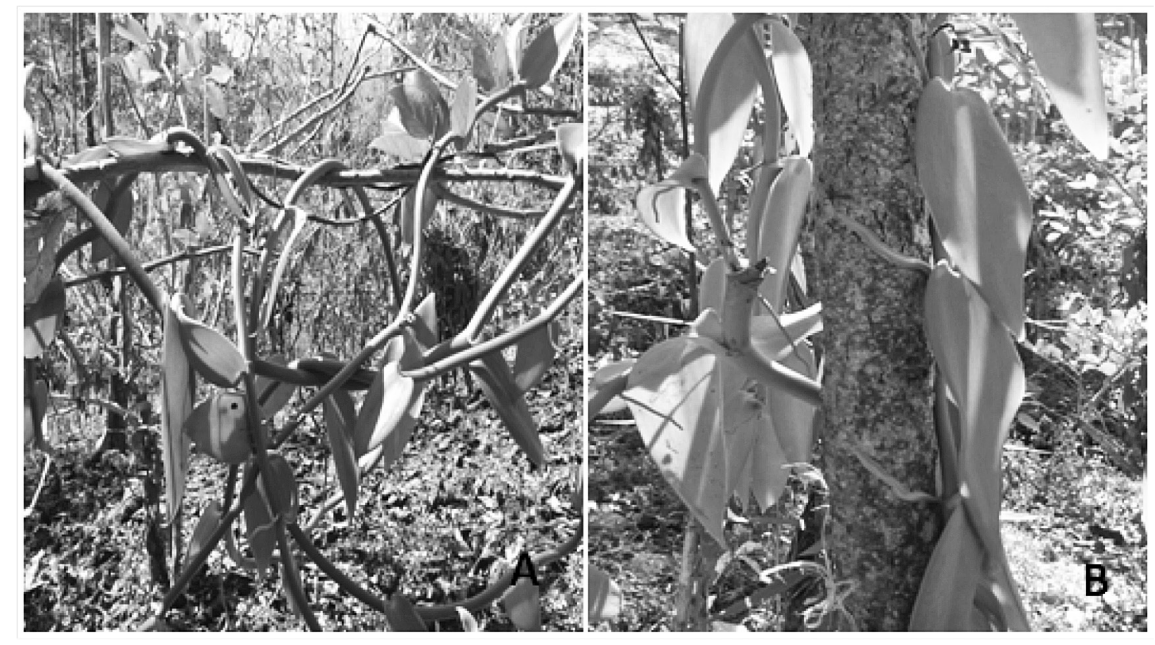

Figura 1. Plantación de Vainilla planifolia en sistema agroforestal, Bocana de Puriscal: A) planta de vainilla en sistema de barbacoa natural, B) planta de vainilla en un tutor de poró.

Sin embargo, aunque la muestra 10 estaba inmersa en un sistema agroforestal en asociación con especies como poró, Vochisya guatemalensis (chancho), y Terminalia amazonia, entre muchas otras, esta finca no hacía monitoreo de las condiciones de humedad ni de estancamientos de agua. La formación de encharcamientos dentro de la plantación contribuye a la aparición de plagas y enfermedades como F. oxysporum (Chaverri, 2013). Esto es de gran interés, dado que, como se muestra en la figura 2, esta plantación de Guápiles resguardaba material de vainilla ( $V$. planifolia y $V$. pompona) tanto sano como enfermo (muestra 11). 


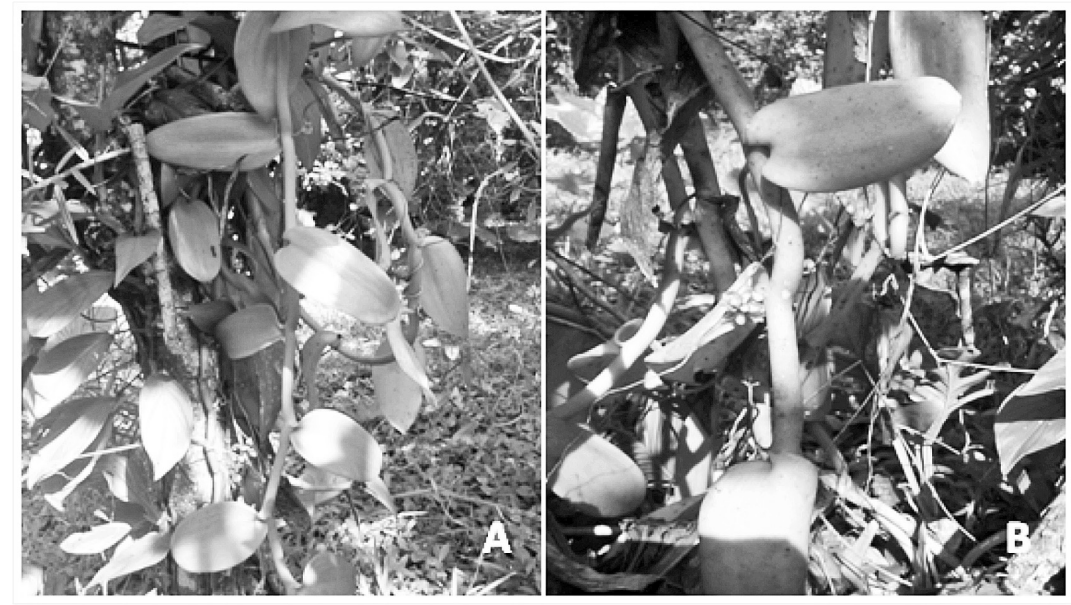

Figura 2. Plantación de vainilla en sistema agroforestal, La Colonia de Guápiles: A) planta de Vainilla planifolia fisiológicamente estable, B) planta de Vainilla pompona enferma con Fusarium oxysporum.

\section{Aislamiento y purificación de bacterias endófitas}

Una vez recolectado el material de vainilla, se procedió a ejecutar el protocolo de desinfección y aislamiento de bacterias endófitas. Debido a que los endófitos viven dentro de los espacios intercelulares de las plantas, la clasificación de una bacteria o un hongo como organismo endófito se basa en su recuperación a partir de material vegetal y semillas adecuadamente esterilizadas en su superficie. Por lo tanto, la detección con éxito de bacterias endófitas en las plantas depende de un procedimiento adecuado de esterilización de la superficie; además, la planta debe volver a infectarse con la cepa endofítica, así como otras cepas de la especie, ya que estas comparaciones permitirán establecer la unicidad de una cepa como un endófito o la singularidad de endofitismo dentro de la especie (Bacon y Hinton, 2007).

A partir de las 11 muestras analizadas, se evaluó el número de bacterias morfológicamente diferentes según color, tamaño y forma de las colonias y se aislaron en cultivos puros. La dilución de los macerados ayudó a bajar la concentración de microorganismos presentes, para obtener distintas colonias dentro de la misma placa Petri pero distantes entre ellas (Madigan, Martinko, Dunlap y Clark, 2009), a fin de utilizarlas en las pruebas de antagonismo, como se presenta en el cuadro 2.

En el cuadro anterior, el crecimiento en Agar Papa Dextrosa y Agar Nutritivo se evaluó tanto para las diluciones $10^{-1}$ como $10^{-2}$.

La mayoría de las especies de endófitos pertenecen a las familias Acetobacteraceae, Enterobacteriaceae, Spirillaceae y Bacillaceae. Por lo tanto, las especies de los géneros Acetobacter, Achromobacter, Burkholderia, Campylobacter, Corynebacterium, Cytophaga, Bacillus, Brevibacterium, Flawobacterium, Leuconostoc, Klebsiella, Micrococcus, Enterobacter, Azospirillum y Erwinia se han asociado con óvulos, semillas, vainas, raíces, hojas y tallos de varias plantas de importancia económica, y estas bacterias han demostrado desempeñar un rol positivo o no tener efecto aparente sobre la supervivencia de varias especies de plantas (Ferrando y Fernández-Scavino, 2013).

\section{Pruebas de antagonismo in vitro}

El nicho endofítico ofrece una oportunidad única para el control de patógenos. El endófito está protegido dentro de la planta y se multiplica en los espacios intercelulares cuando la planta 
crece. La asociación es a largo plazo, lo que sugiere una aplicación para cultivos perennes, tales como la vainilla. El principal uso de las bacterias endofíticas se relaciona con el control de enfermedades en plantas. La alta diversidad de bacterias endofíticas que se conocen podría explicar el gran número de mecanismos de control de una enfermedad que presenta una especie vegetal, entre los que se incluyen la producción de compuestos antimicrobianos, la competencia por macronutrientes y micronutrientes, el hiperparasitismo y la resistencia sistémica adquirida (Rathod et al., 2013).

Cuadro 2. Resultados del aislamiento de bacterias endófitas de Vanilla sp. y de su capacidad in vitro para inhibir el crecimiento del hongo Fusarium oxysporum.

\begin{tabular}{|c|c|c|c|c|c|}
\hline $\begin{array}{c}N^{\circ} \text { muestra } \\
\text { de vainilla }\end{array}$ & $\begin{array}{c}\text { Crecimiento en } \\
\text { PDA }\end{array}$ & $\begin{array}{c}\text { Crecimiento en } \\
\text { AN }\end{array}$ & $\begin{array}{c}N^{\circ} \text { colonias } \\
\text { aisladas }\end{array}$ & $\begin{array}{c}N^{\circ} \text { colonias } \\
\text { seleccionadas para la } \\
\text { prueba in vitro }\end{array}$ & $\begin{array}{c}\text { Resultado prueba } \\
\text { de antagonismo } \\
\text { in vitro }\end{array}$ \\
\hline 1 & + & + & 6 & 4 & - \\
\hline 2 & - & + & 5 & - & - \\
\hline 3 & - & - & - & 4 & - \\
\hline 4 & - & + & 4 & 2 & - \\
\hline 5 & - & + & 2 & 2 & - \\
\hline 6 & - & + & 6 & 6 & - \\
\hline 7 & - & + & 2 & 2 & - \\
\hline 8 & - & + & 2 & 2 & + \\
\hline 9 & - & + & 2 & 2 & Muestra B1M11 \\
\hline 10 & - & + & 4 & & $\left(10^{-1}\right)$ \\
\hline
\end{tabular}

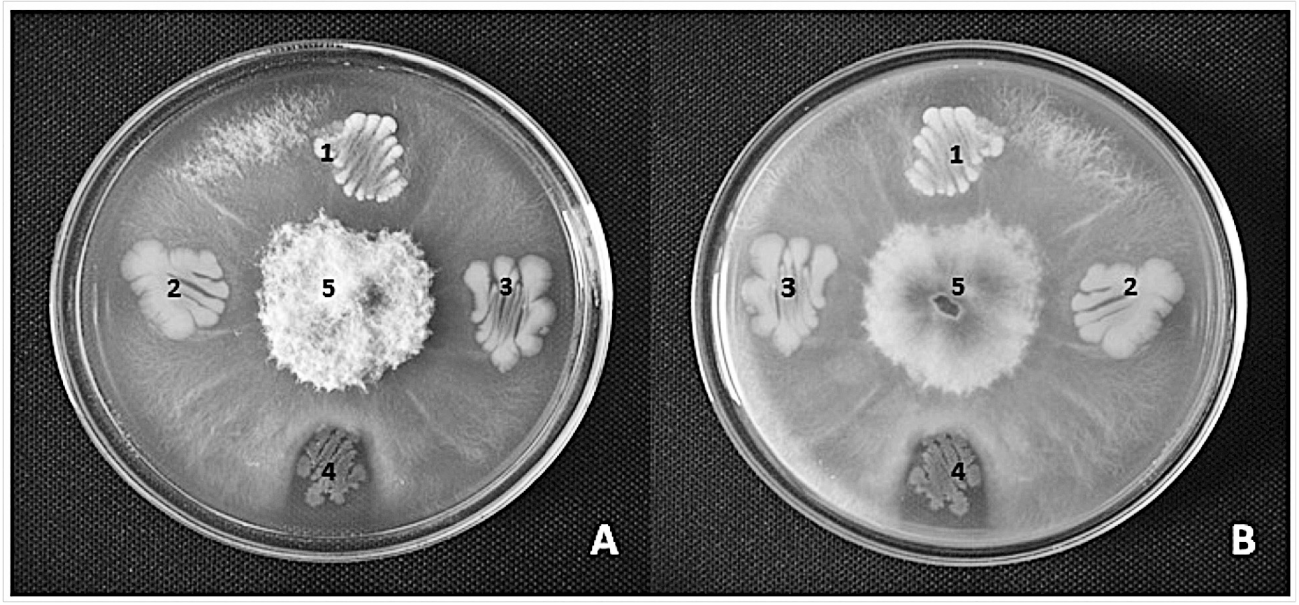

Figura 3. Prueba de antagonismo in vitro entre el hongo Fusarium oxysporum (5) y cuatro bacterias endófitas

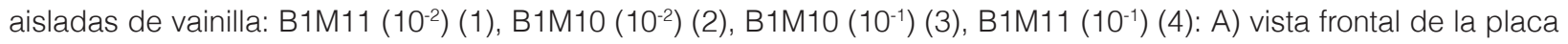
Petri, B) vista inversa de la placa Petri. 
Para efectos de esta investigación, la muestra 11 presentaba un estado fisiológico deteriorado, como se mencionó en el cuadro 1 y como se observa en la figura 2; entonces, tomando en cuenta la enfermedad de la planta y que esta presentaba al menos una bacteria endófita con capacidad de defensa, se tienen entonces indicios de una relación de incompatibilidad entre la planta y el patógeno, ya que esta parece estar generando mecanismos de defensa contra el microorganismo invasor a pesar de que éste ya ingresó (Stella, 2010).

Tras aclarar que las muestras 10 y 11 son un segmento sano y uno enfermo, respectivamente, de una misma planta, se podría inferir que la planta como tal posee bacterias endófitas que participan en la defensa frente al fitopatógeno y por eso el resultado positivo en la prueba de antagonismo, pero quizá, en este caso, la bacteria endófita se encontraba en una baja concentración en el momento que el hongo penetró el tejido y no logró evitar la enfermedad, por lo que se podrían buscar maneras de potenciar naturalmente esa bacteria endófita en la vainilla.

En general, los factores que favorecen el ingreso de microorganismos fitopatógenos en la vainilla son múltiples y pasan de los genéticos a los ambientales, pero se concuerda en que las variedades comerciales de vainilla disponibles en el mercado tienen tejidos ricos en nutrientes que las hacen muy susceptibles a las infecciones causadas por hongos y bacterias; esto se aúna a que la polinización manual de la vainilla, aunque es muy efectiva, si excede el número de flores fertilizadas según la capacidad de la planta, ésta se debilita y es igualmente susceptible al ataque de patógenos (Paniagua, 2013).

\section{Selección de la cepa bacteriana con potencial biocontrolador}

La cepa bacteriana identificada como B1M11 (10-1) fue la única que se perfiló como candidata promisoria para responder al ataque del hongo patógeno F. oxysporum. Esto se determinó mediante la aparición de un halo de inhibición del crecimiento del hongo en placa, como se observa en la figura 3. El halo se presenta como un cese en el crecimiento del hongo alrededor de la bacteria, de manera que el micelio no alcanza a entrar en contacto con ella y genera una región en la que se observa únicamente el medio de cultivo, como línea divisoria entre ambos microorganismos.

Se debe continuar con las pruebas bioquímicas y moleculares para la identificación de esta bacteria, ya que los estudios ecofisiológicos de las relaciones huésped-endófito requieren el análisis de genes reporteros para la cuantificación de actividad transcripcional y metabólica. Los genes reporteros comúnmente usados codifican proteínas cuya expresión se detecta fácilmente mediante mediciones rápidas, sensibles, altamente específicas, cuantitativas y reproducibles. Estos incluyen cloranfenicol acetiltransferasa, P-galactosidasa, luciferasa, P-gluconidase (GUS) y la proteína verde fluorescente (Bacon y Hinton, 2007). Además, las pruebas moleculares permitirán un mayor conocimiento de la expresión de genes en cultivos perennes y pueden proporcionar una mejor comprensión de la resistencia inducida en las plantas (Rathod et al., 2013).

\section{Conclusiones}

- La cepa bacteriana identificada como B1M11 (10-1) es una candidata promisoria para responder al ataque del hongo patógeno F. oxysporum.

- Los híbridos de vainilla producto del cruce de V. planifolia y V. pompona parecen ser igualmente susceptibles a las infecciones causadas por el hongo F. oxysporum.

- Para el aislamiento de bacterias endófitas promisorias en vainilla, se puede utilizar material que presente el inicio de la sintomatología causada por el ataque de F. oxysporum. 


\section{Bibliografía}

Bacon, C. \& Hinton, D. (2007). Isolation in Planta Detection, and Uses of Endophytic Bacteria for Plant Protection. (pp. 638-651). En C. Hurst. Manual of Environmental Microbiology. 3 ed. Santiago de Cali, Colombia. Bhai, S.

Dhanesh, J. (2008). Occurrence of fungal diseases in vanilla (Vanilla planifolia Andrews) in Kerala. Journal of Spices and Aromatic crops, 17(2), 140-148.

Carrillo, L. (2003). Los hongos de los alimentos y forrajes. Fusarium. Salta, Argentina: Editorial de la Universidad Nacional de Salta.

Chaverri, G. (2013). Cultivo de vainilla orgánica en sistemas agroforestales. Experiencias en el cultivo de vainilla. San José: INISEFOR-Colegio de Ingenieros Agrónomos.

Ferrando, L. \& Fernández-Scavino, A. (2013). Functional Diversity of Endophytic Bacteria. (pp. 195-211). En R. Aroca. Symbiotic Endophytes: Soil Biology. Granada, España: Springer.

Gätjens, O. \& Montero, W. (2012). Desarrollo de una nueva metodología de transformación genética no tradicional, como estrategia potencial para inducir resistencia a infecciones fúngicas en vainilla (Vanilla planifolia). San Carlos, Costa Rica. Informe final a la VIE. ITCR.

González, M., Lázaro, C., Engelmann, F., Gámez, R., Martínez, Y., Pastelin, M. \& Díaz, C. (2009). Multiplication and cryopreservation of vanilla (Vanilla planifolia 'Andrews'). In Vitro Cell. Dev. Biol. Plant, 45, 574-582.

Kistler, C. (1997). Genetic diversity in the plant-pathogenic fungus Fusarium oxysporum. Phiytopathology, 87, 474-479.

Madigan, M., Martinko, J., Dunlap, P. \& Clark, D. (2009). Brock: Biología de los Microorganismos. 12 ed. Madrid: Pearson Education.

Melnick, R., Bailey, B. \& Backman, P. (2012). Bacterial Endophytes of Perennial Crops for Management of Plant Disease. (pp. 49-75). En D. Maheshwari, M. Saraf, A. Aeron. Bacteria in Agrobiology: Crop Productivity. Ahmedabad, India: Springer.

Olivares, H. (2010). Sombra artificial y aplicación de thidiazurón en el crecimiento y fisiología de la vainilla (Vanilla planifolia Andrews). Tesis Maestría. Texcoco, México. Campus Montecillo.

Paniagua, A. (2013). Cultivo de vainilla orgánica en sistemas agroforestales. Introducción al cultivo de vainilla. San José: INISEFOR-Colegio de Ingenieros Agrónomos.

Paniagua, A., Villalba, V. \& Montero, L. (2011). Desarrollo de sistemas agroforestales como alternativa de producción sostenible para pequeños y medianos productores de la zona Atlántica de Costa Rica. Informe Final al Programa de Regionalización Interuniversitaria. Costa Rica: CONARE.

Rathod, D., Dar, M., Gade, A., Shrivastava, R., Rai, M., \& Varma, A. (2013). Microbial Endophytes: Progress and Challenges. (pp. 101-121). En S. Chandra, H. Lata, A. Varma. Biotechnology for Medicinal Plants. Berlín: Springer.

Stella, A. (2010). Inducción de Resistencia en Plantas. Interacción Planta-Patógeno. San José: IICA.

Varela, E. (2011). Vanilla production in Costa Rica. En D. Havkin-Frenkel, F. Belanger (Eds.), Handbook of vanilla science and technology. lowa: Blackwell Publishing Ltd.

Villalba, V., Moreira, I. \& Díaz, G. (2012). Identificación y estudio molecular de Fusarium sp., agente causal de la marchitez necrótica presente en los sistemas agroforestales en asocio con el cultivo de vainilla (Vainilla sp.). Informe final a la VIE. ITCR. 